\title{
Mobile learning by English literature students: the role of user satisfaction
}

\author{
Ibtihal Hassan Mussa' ${ }^{1}$, Nurhasmiza Abu Hasan Sazalli ${ }^{2}$, Zainudin Hassan ${ }^{2}$ \\ ${ }^{1}$ Alrahma school, Directorate of Education-Karbala, Ministry of Education, Karbala, Iraq \\ ${ }^{2}$ Faculty of Social Sciences and Humanities, Universiti Teknologi Malaysia, Johor Bahru, Malaysia
}

\begin{tabular}{l} 
Article Info \\
\hline Article history: \\
Received Dec 4, 2020 \\
Revised Mar 30, 2021 \\
Accepted Dec 19, 2021 \\
\hline Keywords: \\
Effort expectancy \\
M-learning \\
Performance exepctancy \\
Subjective norms \\
UTUAT
\end{tabular}

\begin{abstract}
The purpose of this study is to determine the predictors of using mobile learning (ML) among English literature students in Iraq. This study assumes that variables of UTAUT such as effort expectacny (EE) and performance expectancy (PE) as well as the subjective norms (SN) from theory of planned behavior (TPB) will affect the behavioral intention (BI) to use ML. $\mathrm{BI}$ and availability (FC) will affect the actual use (AU). In addition, user satisfaction is proposed as a mediating variable between $\mathrm{PE}, \mathrm{EE}$, and $\mathrm{SN}$ with BI. Data of this study was collected using a questionnaire from 240 undergraduate students. The data was analyzed using PLS. The findings showed that PE, EE and SN are important factors for the BI of ML. BI and FC significantly affected the AU. User satisfaction mediated only the effect of $\mathrm{PE}$ and $\mathrm{EE}$ on BI. Easier processes and instruction must be provided by univeristies to enhance the adoption of ML among English literature students.
\end{abstract}

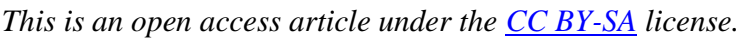

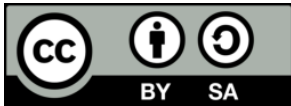

\section{Corresponding Author:}

Ibtihal Hassan Mussa

Alrahma school, Directorate of Education-Karbala

Ministry of Education, Karbala, Iraq

Email: ibtihal.hassan@ymail.com, ibtihal_hassan@karbala.edu.iq

\section{INTRODUCTION}

Mobile learning (ML) is a new and advance technology that its importance has further increased in the time of COVID 19. It is defined as any learning that occurs over the internet using mobile and distance learning [1]. This kind of learning has gained attention again after the outbreak of COVID 19. Several universities around the world are using distance learning to keep their students and academic staff safe [2]. ML is important and beneficial for students and lecturers because it allows learning at anytime from anywhere providing that there is an internet connection and a device such as smartphone to access the internet [3]. ML is widely used in developed countries because these countries enjoy high speed of internet and well-established infrastructure. These are the facilitating conditions that help in using the technology. However, when it come to developing countries and in particular to Iraq, the use of ML is limited and this is due to several issues such as the perception of students about the benefit and the easiness of using the ML as well as the strength of the infrastructure and the internet connection along with the user satisfaction with the technology [4]-[6].

Among the technology acceptance model (TAM) and unified theory of acceptance and use of technology (UTAUT) are highly used in the literature of technology adoption [7]. TAM had been used by most of previous studies and has limitations regarding the explanatory power. It can explain only half of the behavior [8]. On the other hand, UTAUT which has higher explanatory power was utilized in limited number of studies [9]. For this reason, other theorist suggested to include additional variables that can help in 
increasing the explanatory power of the model [10]. Information system success (IS success) predicted that the use of technology is affected by the quality and satisfaction with the service [11]. In addition, the subjective norms ( $\mathrm{SN}$ ) of others on the users is a critical factor for using a technology. An important contextual factor, in the case of Iraq, is the facilitating condition (FC) of the ML [12].

Among the significant application of ML is to practice and master a new language either for fun or because studying the language such as in the English literature studies. Majority of specialist and nonspecialist use the internet and mainly the application in the phone to learn English. English is the language of business and academic research. The importance of English is increasing because it is the language of the science, medicine, tourism, and other fields. In this process, students around the world are studying English as a second language. The use of ML for learning English among undergraduate students has not been widely investigated in developing countries [13], [14]. The fluency of English of the students is low and more practices are needed to strengthen several parts and in particular the speaking and the pronunciation of words correctly. Accordingly, this study aims to examine the factors that affect the use of ML among undergraduate English language literature students in selected universities in Iraq. Iraq is still in the stage of rebuilding and developing the basic infrastructure such as the electricity and the internet connection. However, telecommunication companies in the country are doing well by providing high speed internet and there is a need to examine the factor to understand the enablers of using the technology among students. In the following sections, the literature is discussed followed by the hypothesis's development, methodology, findings, discussion and conclusion.

\section{LITERATURE REVIEW AND CONCEPTUAL MODEL DEVELOPMENT}

ML as well as the theoretical framework of this study along with the proposed framework are discussed.

\subsection{Mobile learning}

ML is a method that is used to connect and attend classes over the internet and using a mobile device [15], [16]. The wide spread of mobile is obvious over the use of laptop and PC. Currently, mobile is used for checking emails, conducting online transaction and learning either by using applications or by attending classes [17], [18]. The use of ML receive much attention during this year (2020) of the outbreak of COVID 19 and the interest is projected to grow due to the consequence of the outbreak [19]. Smartphone now days can do all the function of a computer and their usage in everyday life activities is obvious. Nevertheless, in Iraq, the adoption of technology still in the range of $20 \%$ and students have preference to the traditional method [16], [17], [20]. For this reason, the study will attempt to identify the factor that affect the adoption of ML among Iraqi students.

\subsection{Theoretical framework}

Several theories have been used in the literature of technology adoption. Among the theories, the use of TAM is obvious. However, one of the most comprehensive model is the UTAUT, which predicts that the use of the technology is affected by effort expectancy (similar to PEOU in TAM), performance expectancy (similar to PU in TAM). SNs in TPB and FC [8] are included in this study. IS success proposed that the satisfaction with the service is critical for the usage of a technology [11]. Thus, in this study, the key variables of UTAUT such as the EE, PE, FC as well as the variable of TPB such as SN, and USS from IS success are proposed as important variables to affect the usage of ML by undergraduate English literature students in Iraq.

\subsection{Conceptual framework and hypotheses development}

The literature focused largely on using TAM for technology adoption. In this study, TAM along with other theoretical frameworks are used to develop the conceptual framework. EE and PE are proposed to have direct effect on behavioral intention (BI). In addition, the SN from TPB is expected to have a direct effect on BI while FC and BI are expected to directly affect the actual use (AU). USS is expected to mediate the effect of EE, PE, and SN on BI. Figure 1 shows the conceptual framework.

\subsubsection{Performance expectancy and BI}

$\mathrm{PE}$ is defined as the benefits and privileges that a user can gain from using a technology or a new system [21]. UTAUT proposed that the PE is important variable in the technology usage. In the context of ML, the PE of ML in accessing high quality content of learning material is important for the students to use the technology [18], [22]. Prior literature found that the PE has a significant effect on the BI to use ML [23]-[26]. In this study, it is proposed that PE will have a positive effect on BI to use ML by Iraqi undergraduate English literature students.

H1: PE affects positively the BI to use ML 


\subsubsection{Effort expectacny and $B I$}

The easiness in using the ML is referred to as EE [21]. EE is critical for using any new systems [27], [28]. Clear and simple instructions regarding the usage is important for students to deploy the ML [15], [16], [29]. TAM proposed that EE is a critical factor for the usage of a technology. Previous studies that deployed TAM found that the EE is essential variable for the use of technology such as ML [23]-[26], [29]. In this study, EE is expected to have a positive effect on the BI to use ML.

$\mathrm{H} 2$ : EE affects positively the BI to use ML

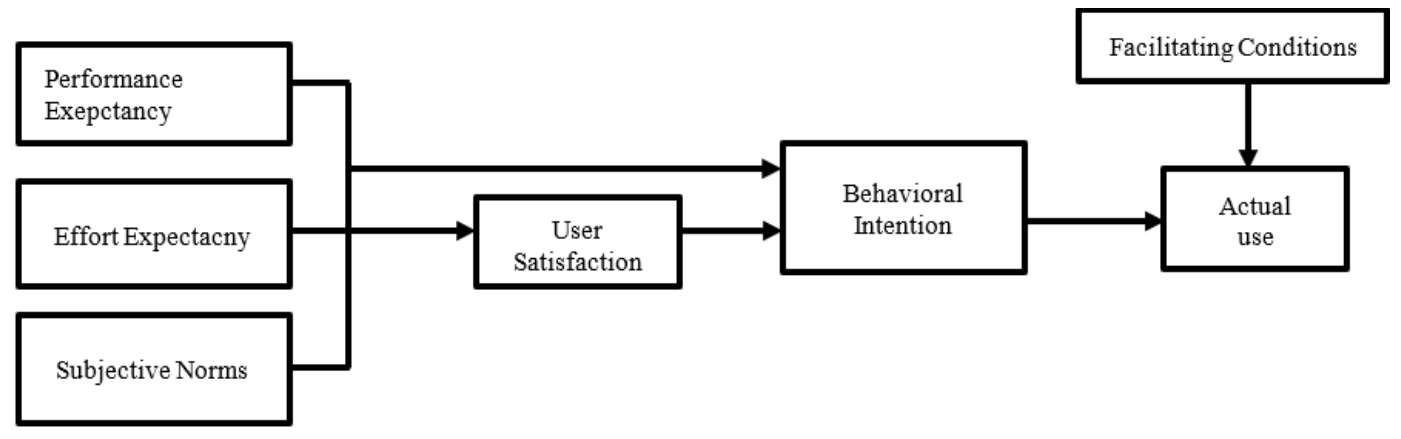

Figure 1. Conceptual framework

\subsubsection{Subjective norms and BI}

The effect of others such as classmate, lecturers, family member, and experts on the decision of students to use ML is known as the SN [30]. TPB indicates that SN at the early stage of introducing new technology is weak and strengthen over time after the spread of the technology [8]. Several studies found that the effect of SN on BI is positive and significant [31], [32]. On the other hand, some of the previous studies indicates that the effect is not significant and it requires more time to feel the effect of others on the decision of the users [33]. In this study, SN is proposed to have important effect on the BI to use ML by Iraqi undergraduate English literature students.

H3: SN has a positive effect on the BI to use ML.

\subsubsection{BI and AU}

$\mathrm{BI}$ refers to "the positive or negative feelings toward using the technology while the AU refers to the action of using or not using the technology" [21], [8]. TAM and UTAUT proposed that the BI is a predictor of AU. Other studies that deployed TAM or UTAUT found that the BI is critical for the AU [34]-[36]. In this study, it is proposed that the BI will have a positive effect on the AU to use ML by Iraqi undergraduate English literature students.

H4: BI affects positively the AU of ML.

\subsubsection{Facilitating conditions and $A U$}

FC refers to the ability to access the ML from anywhere at any time using mobile device [37]. TOE proposed FC as a technological factor and has the ability to determine the usage of a technology. Several previous studies indicates that the FC of infrastructure, internet connection and other factors helps in predicting the AU of a technology [38]-[40]. In this study, FC is proposed to have a direct positive effect on the AU of ML.

H5: FC affects positively the AU of ML.

\subsubsection{Mediating role of USS}

USS is defined as "an affective state that is the emotional reaction to the entire CC experience of a user" [41]. USS with cloud services investigated in few studies [42]. A high quality cloud services is more preferable for active users than low quality services [42]. DeLone and McLean [43] developed the information system success. The authors highlighted the importance of USS with the electronic services to adopt the technology. Researchers have implemented the model of [43] and confirmed the importance of USS for technology acceptance [44]-[46].

Kang et al. [47] proposed that USS with electronic service affects the BI to use electronic services. Park and Ryoo [48] investigated the intention of users to switch toward electronic services and found that USS with the cloud services is an important predictor of the intention to switch to the services. Park and Kim [49] found the USS can mediate the effect among variables. Burda and Teuteberg [41] indicated that satisfaction is critical for trust and PE of cloud. 
There are lack of studies that deal with the mediating role of USS. In the study of [50], [51] USS was found as a mediating variable between quality and the use of electronic systems. Thus, in this study, USS is proposed as a mediating variable between $\mathrm{PE}, \mathrm{EE}$, and $\mathrm{SN}$ with $\mathrm{BI}$.

H6: USS mediates the effect of PE on BI to use ML

H7: USS mediates the effect of EE on BI to use ML

H8: USS mediates the effect of SN on BI to use ML

\section{METHODOLOGY}

This study is a quantitative in nature. A questionnaire was sent to the universities that have agreed to help in the process of data collection. The English literature students in these four Iraqi universities (University of Babylon, University of Kerbala, University of Kufa, University of Wasit) are the population of this study. These four univeristies are the largest in the south of Iraq. In the four universities, there are 3913 English literature students. Thus, these 3913 students are the population of this study. To represent this population, the sample was chosen randomly. This is because the population is homogenous [52]. According to [53], the sample size for a population of 3913 is 350 respondents. The data is collected using a questionnaire. Measurement of the variables were adopted from previous studies. PE (4 items), EE (4 items), BI (5 items), AU (3 items) were adopted from [21]. SN (5 items) was adopted from [54] FC (4 items) was adopted from [55] and USS (4 items) was adopted from [50]. The measurement was validated by three $\mathrm{PhD}$ holders with experience of using $\mathrm{ML}$ and technology adoption and a pilot study was conducted to ensure that the measurements are reliable.

An online questionnaire was sent to students in the four Iraqi universities. The lecturers and the management of the universities were asked for help in distributing the questionnaire. A total of 255 questionnaires were collected. This made the response rate accounts to $72.8 \%$. These responses are sufficient for the use of partial least square (PLS) [56]-[59]. The data examination was conducted to ensure that the data is ready for further analyses and to meet the assumption of structural equation modeling (SEM) analysis. Missing value was assessed using the frequency analysis. A total of 11 responses were deleted due to missing value issue. Outlier was examined and it was found that there is four outliers. This makes the complete and usable dataset account to 240 responses. The normality of the data was examined using Skewness and Kurtosis. Value of Skewness and Kurtosis were greater than absolute 2. For the multicollinearity, the value of tolerance and variation inflation factor (VIF) has met the assumption indicating that there is no collinearity issues.

\section{FINDINGS}

Findings of this study are discussed in this section. It includes the background information of the respondents are given as well as the analysis of smart PLS.

\subsection{Profile of respondents}

A total of 240 undergraduate students have participated in this study. Majority of the respondents (87.5\%) are younger than 25 years. The respondents are males $(78.8 \%)$ who are doing studies in the level of bachelor's degree and have experience of using the ML between 3 to 7 years $(74.5 \%)$.

\subsection{Measurement model}

In PLS, the models are assessed by assessing factor loading (FL), reliabilities and validities [60]. FL for all the variables is greater than 0.70 except for item SN2 form SN, BI1 from BI, EE3 from EE, and FC3 from FC. After deleting the items with low FL, the indices were achieved except for GFI=0.878. However, [60] pointed out that if three of the indices are achieved, they are considered sufficient. In term of the cronbach's alpha (CA), and composite reliabilities (CR), both reliabilities are greater than 0.70 . The average variance extracted (AVE) for all the variables is greater than 0.50 indicating that the convergent validity is achieved. For the discriminant validity, it is achieved because the square root of AVE is greater than the cross loading. Table 1 shows the results of assessing the measurement model.

Table 1. Reliabilities and validities of the measurement model.

\begin{tabular}{cccccccccr}
\hline & CA & CR & AVE & AU & BI & EE & FC & PE & SN \\
\hline AU & 0.91 & 0.94 & 0.79 & 0.89 & & & & & \\
BI & 0.89 & 0.93 & 0.81 & 0.45 & 0.90 & & & \\
EE & 0.94 & 0.96 & 0.84 & 0.36 & 0.48 & 0.92 & & \\
FC & 0.88 & 0.92 & 0.74 & 0.21 & 0.26 & 0.13 & 0.86 & 0.90 & \\
PE & 0.92 & 0.95 & 0.81 & 0.29 & 0.50 & 0.62 & 0.09 & 0.58 & 0.87 \\
SN & 0.84 & 0.90 & 0.76 & 0.36 & 0.48 & 0.57 & 0.23 & 0.44 \\
USS & 0.89 & 0.93 & 0.82 & 0.43 & 0.51 & 0.42 & 0.34 & 0.45 & 0.91 \\
\hline
\end{tabular}

Note: PE: perceived usefulness, EE: perceived ease of use, SN: subjective norms, USS: user satisfaction, FC: facilitating conditions, BI: behavioral intention, AU: Actual use, CR: cronbach's alpha, CR: composite reliability, AVE: average variance extracted. 


\subsection{Structural model}

In assessing the structural model there are two important criteria that are the R-square and the path coefficient [60]. The value of R-square $0.25,0.50,0.75$ is considered weak, moderate, and substantial respectively. In this study, the R-square accounted to .73 indicating that $73 \%$ of the variation of $\mathrm{AU}$ can be explained by the variables of this study. The structural model of direct effect and mediating model were examined. Figure 2 shows the structural model of this study. It can be seen that all the indices were achieved.

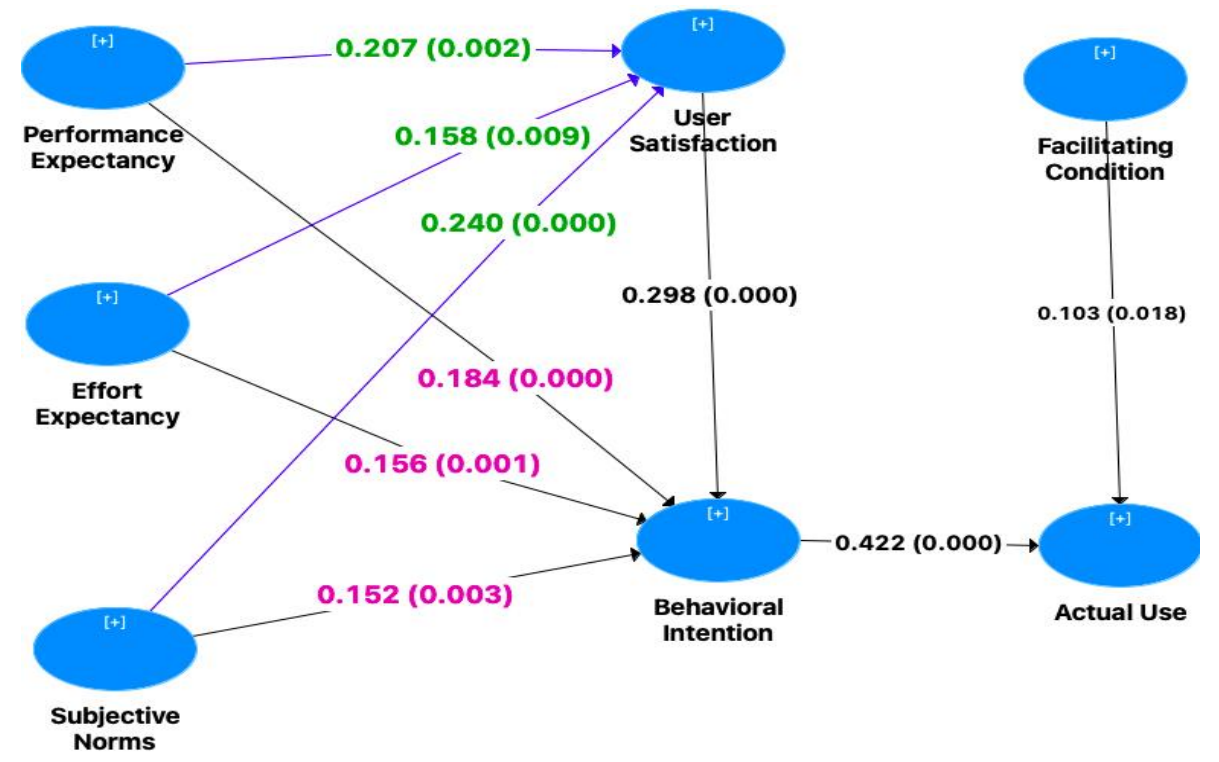

Figure 2. Structural model

\subsection{Results of hypotheses}

This study included direct and mediating effect hypotheses. The direct effect was examined first followed by the mediating effect. Table 2 shows the results of testing the hypotheses. For the effect of PE on BI, the finding in Table 2 shows that it is significant. Similarly, for the EE and SN they have important effect on the $\mathrm{BI}$ of the students suggesting that $\mathrm{H} 2$ and $\mathrm{H} 3$ are supported. For $\mathrm{H} 4$ and $\mathrm{H} 5$ they are also supported because the effects of $\mathrm{BI}$ and $\mathrm{FC}$ on $\mathrm{AU}$ are significant. The mediator was tested by comparing the direct effect with the indirect effect. The results show that there is a mediation. However, the mediation is partial. Thus, H6 is partially supported. For $\mathrm{H} 7$, it also shows that USS partially mediated the effect of EE on BI. In addition, USS did mediate the effect of SN on BI. This is because the indirect effect is significant. Thus, H8 is supported.

Table 2. Results of hypotheses testing

\begin{tabular}{|c|c|c|c|c|c|}
\hline & & $\beta$ & StD. & T-value & $\mathrm{P}$ values \\
\hline \multicolumn{6}{|c|}{ Direct effect } \\
\hline H1 & $\mathrm{PE}->\mathrm{BI}$ & 0.18 & 0.05 & 3.49 & 0.00 \\
\hline $\mathrm{H} 2$ & $\mathrm{EE}->\mathrm{BI}$ & 0.16 & 0.05 & 3.42 & 0.00 \\
\hline H3 & $\mathrm{SN}->\mathrm{BI}$ & 0.15 & 0.05 & 2.98 & 0.00 \\
\hline $\mathrm{H} 4$ & $\mathrm{BI} \rightarrow \mathrm{AU}$ & 0.42 & 0.05 & 9.37 & 0.00 \\
\hline H5 & $\mathrm{FC} \rightarrow \mathrm{AU}$ & 0.10 & 0.04 & 2.36 & 0.02 \\
\hline \multicolumn{6}{|c|}{ Indirect effect } \\
\hline H6 & $\mathrm{PE}->\mathrm{USS}->\mathrm{BI}$ & 0.06 & 0.02 & 2.82 & 0.00 \\
\hline $\mathrm{H} 7$ & EE $->$ USS $>$ BI & 0.05 & 0.02 & 2.37 & 0.02 \\
\hline H8 & SN $->$ USS $->$ BI & 0.07 & 0.02 & 3.42 & 0.00 \\
\hline
\end{tabular}

\section{DISCUSSION AND IMPLICATIONS}

The current study aimed to find the factors that impact the undergraduate English literature students to deploy the technology of ML in learning English language. Based on existing theories and frameworks, this study proposed that PE, EE, SN will have a direct effect on BI. In addition, the study proposes that BI and FC will affect the AU. USS was proposed as a mediating variable between PE, EE, SN and BI. The data was collected from 240 undergraduate students. The findings using PLS showed that the effects of PE, EE, and SN on BI are positive and significant. These finding are in line with the TAM model which proposes that $\mathrm{PE}$ and $\mathrm{EE}$ are critical for the usage of a technology. they are also in line with the findings of previous studies 
[23]-[26], [29]. The findings indicates that the PE is essential for students. Universities are recommended to increase the benefits and the way of teaching English for students. This can be by including material that enhances the learning such as to include short movies with clear English and subtitle. Universities also can include quiz, exercises, and increase the students' participation in a class using the ML so that the students can better perceive the benefit from ML.

The EE is also critical factor for the ML. Universities in Iraq are advised to ease the process of log in as well as the process of downloading and uploading files using the ML. The easier the system, the more positive BI will be generated by the students. SN is also among the important variable for using ML. It seems that the ML has its base in Iraq and the effect of SN on the BI is significant. This indicates that peers, classmate, lecturers, and management of the universities are in favor of using the ML and has to some degree influence on the decision of students to use the technology. However, the effect of SN on BI is lower compared with PE and EE. This finding is in line with the UTAUT which predicts that the effect of SN in the introduction phase of the technology is low, and it strengthens over time. For the FC and BI, they have a significant critical effect on the AU. FC is important in the context of Iraq. The ability to use the ML from anywhere at any time is vital for using the technology and it requires to be supported at the university and government level. High speed internet should be provided in the campus and the government should ensure that electricity and internet are available for students in their houses and campus of the universities. The findings are in line with the IS success model, which predicted that USS with the technology is important for the increase in the use of the technology.

\section{CONCLUSION}

This study was conducted in Iraq among undergraduate students of English literature. The findings showed that PE is the most important factor followed by EE and SN. FC as well as BI affected the AU while USS mediated partially the effect of PE and EE on BI. The finding is limited to the perception of undergraduate English literature students. It is also limited in term of sample size to 240 students. However, these responses are sufficient for the use of PLS. Only four universities were included in this study due to the time and the FC. As a future work, it is suggested that research should examine the use of ML among other students in other filed. Researchers are also suggested to include more universities such as private and public universities. More studies are needed in developing countries to assess the goodness of ML and the predictors of the wide usage of this technology.

\section{REFERENCES}

[1] W. G. Alghabban, R. M. Salama and A. H. Altalhi, "Mobile cloud computing: An effective multimodal interface tool for students with dyslexia," Computers in Human Behavior, vol. 75, pp. 160-166, 2017, doi: 10.1016/j.chb.2017.05.014.

[2] O. B. Al-Ghraibah, "Online Consumer Retention In Saudi Arabia During COVID 19: The Moderating Role Of Online Trust," Journal of Critical Reviews, vol. 7, no. 9, pp. 2464-2472, 2020.

[3] O. A. Abdulsattar, "Performance in Construction Industry In Post- Conflict Situations-Iraq As A Case Study," American Journal of Engineering Research AJER, no. 9, pp. 188-195, 2017.

[4] M. A. Mohammed, I. Huda and M. N. Maslinda, "Electronic information sharing between public universities and ministry of higher education and scientific research: A pilot study," Journal of Theoretical and Applied Information Technology, vol. 77, no. 2, pp. 151-163, 2015.

[5] M. A. Wahsh and J. S. Dhillon, "An investigation of factors affecting the adoption of cloud computing for E-government implementation," IEEE Student Conference on Research and Development SCOReD, 2015, pp. 323-328, doi: 10.1109/SCORED.2015.7449349.

[6] A. H. Morad, "The Reality of University Education in Iraq: Problems and Solutions Through Adoption of Credit Hours System," Engineering and Technology Journal, vol. 37, no. 4C, pp. 487-491, 2019, doi: 10.30684/etj.37.4C.18.

[7] I. H. Mussa, "Mobile Learning adoption in the Middle East: Limitations, Challenges and Features of the Mobile Devices," International Journal of Contemporary Management and Information Technology, vol. 1, no. 1, pp. 30-36, 2020.

[8] V. Venkatesh, M. G. Morris, G. B. Davis and F. D. Davis, "User Acceptance of Information Technology: Toward a Unified View," MIS Quarterly, vol. 27, no. 3, pp. 425-478, 2003, doi: 10.2307/30036540.

[9] M. Kayali and S. Alaaraj, "Adoption of Cloud Based E-learning in Developing Countries: A Combination A of DOI, TAM and UTAUT," International Journal of Contemporary Management and Information Technology, vol. 1, no. 1, pp. 1-7, 2020.

[10] S. K. Sharma, A. H. Al-Badi, S. M. Govindaluri and M. H. Al-Kharusi, "Predicting motivators of cloud computing adoption: A developing country perspective," Computers in Human Behavior, vol. 62, pp. 61-69, 2016, doi: 10.1016/j.chb.2016.03.073.

[11] W. H. DeLone and E. R. McLean, "Information Systems Success Measurement," NOW The Essence of Knowledge, vol. 2, no. 1, pp. 1-32, 2016.

[12] I. H. Mussa and A. S. Izkair, "The acceptance of using Mobile assisted language among EFL and ESL students," International Journal Contemporary Applied Science, vol. 4, no. 5, pp. 1-11, 2017.

[13] N. Thongsri, L. Shen, Y. Bao and I. M. Alharbi, "Integrating UTAUT and UGT to explain behavioural intention to use Mlearning," Journal of Systems and Information Technology, vol. 20, no. 3, pp, 278-297, 2018, doi: 10.1108/JSIT-11-2017-0107.

[14] M. Al-Emran, V. Mezhuyev and A. Kamaludin, "Is M-learning acceptance influenced by knowledge acquisition and knowledge sharing in developing countries?," Education and Information Technologies, vol. 26, pp. 2585-2606, 2021.

[15] A. M. Abdelaziz, "The Role of Mobile Learning in Developing Employability and Job-Related Skills at VTET Programs," Developing Countries and Technology Inclusion in the 21st Century Information Society, IGI Global, pp. 99-122, 2021, doi: 10.4018/978-1-7998-3468-7.ch006. 
[16] S. O. Ugbaje, K. Ardzejewska, A. Imran, A. Yakubu and M. Yakubu, "Cloud-Based M-Learning: A Pedagogical Tool to Manage Infrastructural Limitations and Enhance Learning," International Journal of Education and Development using Information and Communication Technology, vol. 16, no. 2, pp. 48-67, 2020.

[17] A. Alsswey, H. Al-Samarraie, F. A. El-Qirem and F. Zaqout, "M-learning technology in Arab Gulf countries: A systematic review of progress and recommendations," Education and Information Technologies, vol. 25, pp. 2919-2931, 2020.

[18] A. R. Pratama, "Fun first, useful later: Mobile learning acceptance among secondary school students in Indonesia," Education and Information Technologies, vol. 26, pp. 1737-1753, 2021

[19] N. Doghonadze, "The Degree of Readiness to Total Distance Learning in the Face of COVID-19-Teachers' View (Case of Azerbaijan, Georgia, Iraq, Nigeria, UK and Ukraine),” IJCMIT, vol. 5, no. 2, pp. 1-8, 2020, doi: 10.31578/jebs.v5i2.197.

[20] A. Al-Azawei and A. Alowayr, "Predicting the intention to use and hedonic motivation for mobile learning: A comparative study in two Middle Eastern countries," Technology in Society, vol. 62, p. 101325, 2020, doi: 10.1016/j.techsoc.2020.101325.

[21] F. D. Davis, "Perceived Usefulness, Perceived Ease of Use and User Acceptance of Information Technology," MIS Quartely, vol. 13, no. 3, pp. 319-340, 1989, doi: 10.2307/249008.

[22] A. Qashou, "Influencing factors in M-learning adoption in higher education," Education and Information Technologies, vol. 26, pp. 1755-1785, 2020.

[23] A. Aman, L. D. Prasojo, M. Sofwan, A. Mukminin, A. Habibi and L. N. Yaqin, "Factors affecting indonesian pre-service teachers' use of m-LMS: A mix method study," International Journal Interaction Mobile Technology, vol. 14, no. 6, pp. 137-147, 2020, doi: 10.3991/ijim.v14i06.12035.

[24] A. Mukminin, A. Habibi, M. Muhaimin and L. D. Prasojo, "Exploring the Drivers Predicting Behavioral Intention to Use mLearning Management System: Partial Least Square Structural Equation Model,” IEEE Access, vol. 8, pp. 181356-181365, 2020, doi: 10.1109/ACCESS.2020.3028474.

[25] A. Q. M. AlHamad, "Predicting the Intention to use Mobile Learning: A Hybrid SEM-Machine Learning Approach," International Journal of Engineering Research \& Technology, vol. 9, no. 3, pp. 275-282, 2020.

[26] M. Al-Emran, I. Arpaci and S. A. Salloum, "An empirical examination of continuous intention to use m-learning: An integrated model," Education and Information Technologies volume, vol. 25, pp. 2899-2918, 2020.

[27] M. Kaiiali, S. Sezer and A. Khalid, "Cloud computing in the quantum era," IEEE Conference on Communications and Network Security CNS, 2019, pp. 1-4, doi: 10.1109/CNS44998.2019.8952589.

[28] M. Kaiiali, A. Iliyasu, A. S. Wazan, A. Habbal and Y. I. Muhammad, "A Cloud-based Architecture for Mitigating Privacy Issues in Online Social Networks," International Arab Journal of Information Technology, pp. 1-10, 2019.

[29] M. Alshurideh, B. Al Kurdi, S. A. Salloum, I. Arpaci and M. Al-Emran, "Predicting the actual use of m-learning systems: a comparative approach using PLS-SEM and machine learning algorithms," Interactive Learning Environments, pp. 1-15, 2020, doi: 10.1080/10494820.2020.1826982.

[30] V. Venkatesh, F. K. Y. Chan, S. a Brown, P. J. Hu, K. Y. Tam and J. Thong, "Modeling Citizen Satisfaction with Mandatory Adoption of an E-Government Technology," Journal of the Association for Information Systems, vol. 11, no. 10, pp. 519-549, 2011.

[31] F. Asmi, R. Zhou and L. Lu, "E-government Adoption in Developing Countries: Need of Customer-centric Approach: A Case of Pakistan," International Business Research, vol. 10, no. 1, pp. 42-58, 2017, doi: 10.5539/ibr.v10n1p42.

[32] Q. Zhou, L. F. Martinez, A. I. Ferreira and P. Rodrigues, "Supervisor support, role ambiguity and productivity associated with presenteeism: A longitudinal study," Journal of Business Research, vol. 69, no. 9, pp. 3380-3387, 2016, doi: 10.1016/j.jbusres.2016.02.006

[33] M. N. Yakubu and S. I. Dasuki, "Factors affecting the adoption of e-learning technologies among higher education students in Nigeria: A structural equation modelling approach," Information Development, vol. 35, no. 3, pp. 492-502, 2019.

[34] F. Ali, P. K. Nair and K. Hussain, "An assessment of students' acceptance and usage of computer supported collaborative classrooms in hospitality and tourism schools," Journal of Hospitality, Leisure, Sport \& Tourism Education, vol. 18, pp. 51-60, 2016, doi: 10.1016/j.jhlste.2016.03.002.

[35] T. S. Behrend, E. N. Wiebe, J. E. London and E. C. Johnson, "Cloud computing adoption and usage in community colleges," Behaviour \& Information Technology, vol. 30, no. 2, pp. 231-240, 2011, doi: 10.1080/0144929X.2010.489118.

[36] H. M. Sabi, F. M. E. Uzoka, K. Langmia and F. N. Njeh, "Conceptualizing a model for adoption of cloud computing in education," International Journal of Information Management, vol. 36, no. 2, pp. 183-191, 2016, doi: 10.1016/j.ijinfomgt.2015.11.010.

[37] S. Kim and G. Garrison, "Investigating mobile wireless technology adoption: An extension of the technology acceptance model," Information Systems Frontiers, vol. 11, no. 3, pp. 323-333, 2009.

[38] N. Phaphoom, X. Wang, S. Samuel, S. Helmer and P. Abrahamsson, "A survey study on major technical barriers affecting the decision to adopt cloud services," Journal of Systems and Software, vol. 103, pp. 167-181, 2015, doi: 10.1016/j.jss.2015.02.002.

[39] N. Alkhater, G. Wills and R. Walters, "Factors Influencing an Organisation's Intention to Adopt Cloud Computing in Saudi Arabia," IEEE 6th International Conference on Cloud Computing Technology and Science, 2014, pp. 1040-1044, doi: 10.1109/CloudCom.2014.95.

[40] K. Atchariyachanvanich, N. Siripujaka and N. Jaiwong, "What Makes university students use cloud-based e-learning? Case study of KMITL students," International Conference on Information Society, 2014, pp. 112-116, doi: 10.1109/i-Society.2014.7009022.

[41] D. Burda and F. Teuteberg, "The role of trust and risk perceptions in cloud archiving - Results from an empirical study," The Journal of High Technology Management Research, vol. 25, no. 2, pp. 172-187, 2014, doi: 10.1016/j.hitech.2014.07.008.

[42] S. Ding, Z. Wang, D. Wu and D. L. Olson, "Utilizing customer satisfaction in ranking prediction for personalized cloud service selection," Decision Support Systems, vol. 93, pp. 1-10, 2017, doi: 10.1016/j.dss.2016.09.001.

[43] W. H. DeLone and E. R. McLean, "Information systems success: The quest for the dependent variable," Information Systems Research, 1992, doi: 10.1287/isre.3.1.60.

[44] C. Tam and T. Oliveira, "Understanding the impact of $\mathrm{m}$-banking on individual performance: DeLone \& McLean and TTF perspective," Computers in Human Behavior, vol. 61, pp. 233-244, 2016, doi: 10.1016/j.chb.2016.03.016.

[45] W. H. DeLone and E. R. McLean, "The DeLone and McLean Model of Information Systems Success: A Ten-Year Update," Journal of Management Information Systems, vol. 19, no. 4, pp. 9-30, 2014, doi: 10.1080/07421222.2003.11045748.

[46] C. K. Flack, P. Dembla and S. Petter, "Extending the DeLone and McLean IS Success Model to Cloud Computing," AIS elibrary, 2015.

[47] A. Kang, L. Barolli, J. D. Lee, J. H. Park and H. Y. Jeong, "Information success model for learning system in cloud computing environment," International Joint Conference on Awareness Science and Technology \& Ubi-Media Computing iCAST 2013 \& UMEDIA, 2013, pp. 764-768, doi: 10.1109/ICAwST.2013.6765539.

[48] S. C. Park and S. Y. Ryoo, "An empirical investigation of end-users' switching toward cloud computing: A two factor theory perspective," Computers in Human Behavior, vol. 29, no. 1, pp. 160-170, 2013, doi: 10.1016/j.chb.2012.07.032. 
[49] E. Park and K. J. Kim, “An integrated adoption model of mobile cloud services: Exploration of key determinants and extension of technology acceptance model," Telematics and Informatics, vol. 31, no. 3, pp. 376-385, 2014, doi: 10.1016/j.tele.2013.11.008.

[50] H.-J. Lee and J.-H. Lim, "The Effect of Quality Factors of Accounting Information System on Management Performance-Focused on Mediating Role of User Satisfaction and Education Training Performance," Journal of the Korea Industrial Information Systems Research, vol. 23, no. 2, pp. 41-52, 2018, doi: 10.9723/jksiis.2018.23.2.041.

[51] T. Kincl and P. Šrach, "Measuring website quality: asymmetric effect of user satisfaction," Behaviour \& Information Technology, vol. 31, no. 7, pp. 647-657, 2012, doi: 10.1080/0144929X.2010.526150.

[52] U. Sekaran and R. Bougie, "Research methods for business: A skill building approach," John Wiley \& Sons, 2016.

[53] R. V Krejcie and D. W. Morgan, "Determining Sample Size For Research Activities, Educational And Psychological Measurement," Educational and Psychological Measurement, no. 30, pp. 607-610, 1970, doi: 10.1177/001316447003000308.

[54] V. Venkatesh, H. Bala, "Technology Acceptance Model 3 and a Research Agenda on Interventions," Journal compilation, vol. 39, no. 2, pp. 273-315, 2008.

[55] G. Ramachandran, N., Sivaprakasam, P., Thangamani, G., \& Anand, "Selecting a suitable Cloud Computing technology deployment model for an academic institute," Campus-Wide Information Systems, vol. 31, no. 5, pp. 319-345, 2014, doi: 10.1108/CWIS-09-2014-0018.

[56] S. Alaaraj, Z. A. Mohamed and U. S. Ahmad Bustamam, "External Growth Strategies and Organizational Performance in Emerging Markets: The Mediating Role of Inter-Organizational Trust," Review of International Business and Strategy, vol. 28, no. 2, pp. 206-222, 2018, doi: 10.1108/RIBS-09-2017-0079.

[57] S. Alaarj, Z. A. Mohamed and U. S. A. Bustamam, "Do Knowledge Management Capabilities Reduce the Negative effect of Environment Uncertainties on Organizational Performance? A Study of Public Listed Companies in Malaysia," International Journal of Economic Research, vol. 14, no. 15, pp. 443-456, 2017.

[58] S. Alaarj, Z. A. Mohamed and U. S. A. Bustamam, "The Effect of Knowledge Management Capabilities on Performance of Companies: A Study of Service Sector," International Journal of Economic Research, vol. 14, no. 15, pp. 457-470, 2017.

[59] S. Alaarj, Z. Abidin-Mohamed and U. S. B. A. Bustamam, "Mediating Role of Trust on the Effects of Knowledge Management Capabilities on Organizational Performance," Procedia - Social and Behavioral Sciences, vol. 235, pp. 729-738, 2016, doi: 10.1016/j.sbspro.2016.11.074.

[60] J. F. Hair Jr, M. Sarstedt, L. Hopkins and V. G. Kuppelwieser, "Partial least squares structural equation modeling (PLS-SEM)," European Business Review, vol. 26, no. 2, pp. 106-121, 2014, doi: 10.1108/EBR-10-2013-0128.

\section{BIOGRAPHIES OF AUTHORS}

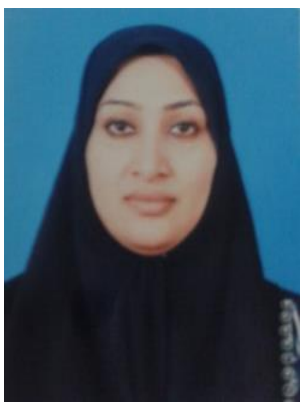

Ibtihal Hassan Mussa (D) $8 \mathrm{SC}$ P has obtained a Master degree in English language studies from UKM University in Malaysia in 2015. She has experience in teaching of English language for about 20 years in the secondary schools in Iraq, she has many certificates and letters of thanks from Ministry of education-Iraq. She has many published research papers about e-learning and mobile learning. She is going to publish many types of research about MALL to enhance the ways of teaching and learning the English language in Iraq by using mobile technology. She can be contacted at email: ibtihal.hassan@ymail.com

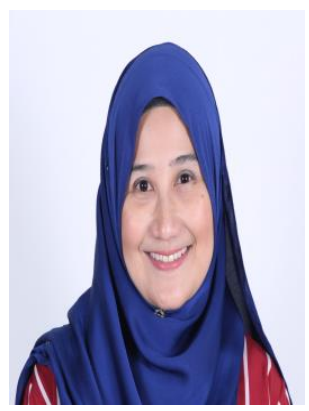

Nurhasmiza Abu Hasan Sazalli (iD ST SC P obtained her PhD in Education, from University of Exeter, UK. She is an active member of the International Association of Mobile Learning and the International Association of Blended Learning. She has 3 masters degree; MBA (Digital Entrepreneurship) (UTM), MSc Educational Research \& M.A English Language Studies (UKM). Her research interests include mobile language learning, design based research, digital marketing, TESL and design thinking. One of her biggest project is the development of mobile apps content for onboarding of all new employees of McDonald's Malaysia. She also assists to map, design, develop and deliver Talent Development Programme for Gerbang Alaf Restaurants Sdn Bhd (McDonald's Malaysia). This prominent project opens up opportunities for McDonald's employees to further their study in UTM Kuala Lumpur that lead them to obtain Master in Business Administration. Optimizing her knowledge in digital learning, Nurhasmiza has coached university academics, school teachers and McDonald's Malaysia to embark on online learning even before the COVID-19 pandemic. With strong believe that digital learning is the way forward, her online learning trainings focus on producing trainers who can conduct as engaging, interactive, meaningful and exciting trainings on digital platforms. She can be contacted at email: nurhasmiza.kl@utm.my

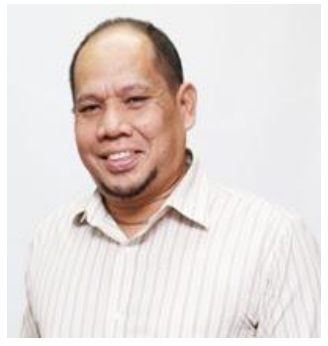

Zainudin Hassan (iD $\mathrm{S}$ SC $\mathrm{P}$ his $\mathrm{PhD}$ in Education from Universiti Teknologi Malaysia where he has been a faculty member since 1992. He is now working at School of Education, Faculty of Social Science and Humanities, Universiti Teknologi Malaysia, Skudai, Johor. He was also coordinator for Education and Development in his faculty. His research interests are primarily in social change, sociology in education, service learning and higher education. $\mathrm{He}$ can be contacted at email: p-zainudin@utm.my. 